\title{
Expected scores in the rod-and-frame test revisited
}

GLEN M. VAUGHT, State University of New York at Oswego, Oswego, N.Y. 13126

$A$ distribution of Rod-and-Frame Test scores for college students is presented as a replication of the Presscy-Vaught data. A discussion follows in which three common procedural problems are related to comparison difficulties.

Recent papers by Pressey (1968) and Vaught (1968) have pointed out the difficulties involved in procuring field-dependent (FD) $\mathrm{Ss}$ in the Rod-and-Frame Test (RFT) when $10 \mathrm{deg}$ or more is used to define FD. In order to test the generality of the above findings for Ss other than college students, Neville, Workman, \& Johnson (1969) reported a frequency distribution of RFT scores for 85 male and 153 female psychiatric inpatients. The Neville et al (1969) frequency distribution turned out to be an inversion of the Pressey-Vaught distributions and was not in keeping with RFT literature (cf. Witkin, 1965; Witkin, Faterson, Goodenough, \& Karp, 1962). The overall magnitude of the disparity between these two sets of data engendered the following considerations: (1) Even though the literature doesn't warrant such a conclusion, there are real differences between RFT scores for college students and psychiatric patients; (2) the Pressey-Vaught samples may not be representative of college-student RFT scores; and (3) there may be methodological and procedural differences between the two sets of data that could account for the observed discrepancies. The purpose of the present report is to provide for a replication of the Pressey-Vaught findings and to discuss three methodological considerations that are thought to influence comparisons between the Neville et al data and the Pressey-Vaught data.

The RFT (Series 3 ) was administered to 92 male and 92 female college students in a lightproof room. $S$ was seated in an upright chair $12 \mathrm{ft}$ in front of the RFT and was required to adjust the rod to the vertical in each of eight trials. All adjustments of the rod were done via a S-operated control switch. The frame was tilted $28 \mathrm{deg}$ to the right or left, and the starting position of the rod was randomized on each trial. The apparatus used in this study was the same RFT used in previous work, an 18-10 RFT manufactured by the Marietta Apparatus Company. S's score was the average deviation, without regard to direction, from true vertical on all eight trials.

The data contained in Table 1 represents an accurate replication of the Pressey (1968) and Vaught (1968) frequency distributions. It is assumed, therefore, that the Pressey-Vaught scores, together with the present set of scores, provide a reasonable representation of college-student performance in the RFT (Series 3). It is also important to note that the three sets of data include $570 \mathrm{male}$ and 564 female college students from at least four different institutions.

Table 1

Frequency Distributions of Scores in the Rod-and-Frame Test (Series 3) for 92 Male and 92 Female College Students

\begin{tabular}{|c|c|c|c|c|}
\hline \multirow[b]{3}{*}{ RET Scores } & \multicolumn{4}{|c|}{ Per Cent of the Cases } \\
\hline & \multicolumn{2}{|c|}{ By Sex } & \multicolumn{2}{|c|}{ Within Sex } \\
\hline & Male & Female & Male & Female \\
\hline $0.0-0.9$ & 3.80 & 1.08 & 7.60 & 2.17 \\
\hline $1.0-1.9$ & 21.73 & 14.13 & 43.47 & 28.26 \\
\hline $2.0-2.9$ & 12.50 & 17.93 & 25.00 & 35.86 \\
\hline $3.0-3.9$ & 5.43 & 4.34 & 10.86 & 8.69 \\
\hline $4.0-4.9$ & 3.26 & 3.80 & 6.52 & 7.60 \\
\hline $5.0-5.9$ & 0.00 & 3.26 & 0.00 & 6.52 \\
\hline $6.0-6.9$ & 1.08 & .54 & 2.17 & 1.08 \\
\hline $7.0-7.9$ & 0.00 & 0.00 & 0.00 & 0.00 \\
\hline $8.0-8.9$ & 0.00 & 0.00 & 0.00 & 0.00 \\
\hline $9.0-9.9$ & 0.00 & .54 & 0.00 & 1.08 \\
\hline $10.0-10.9$ & .54 & 1.08 & 1.08 & 2.17 \\
\hline $11.0-11.9$ & 0.00 & .54 & 0.00 & 1.08 \\
\hline $12.0-12.9$ & .54 & .54 & 1.08 & 1.08 \\
\hline 13.0-over & 1.08 & 2.17 & 2.17 & 4.34 \\
\hline
\end{tabular}

There are possibly three methodological and procedural differences between the Neville et al (1969) report and the Pressey-Vaught reports that could contribute to the observed differences. First, Neville and his colleagues used a head clamp while administering the RFT, but Pressey and Vaught did not employ a head clamp. Lester (1968) has suggested that scores acquired under each of these conditions would not necessarily yield comparable results. Second, Neville et al used a noncommercial RFT, while Pressey and Vaught used a commercial apparatus. It is possible that differences in instrument calibration could influence the scores obtained by Neville et al and thereby contribute to the observed discrepancies. Third, Neville and colleagues manipulated the rod following Ss' instructions, while the Pressey-Vaught data was collected by Ss using a remote-control switch to move the rod. Adevai, Silverman, \& McGough (1968), while reporting a correlation of .83 between the two methods, discuss other studies that have found significant differences.

In view of the large number of Ss involved and in view of the present replication, it seems reasonable to assume that the Pressey-Vaught frequency distributions provide an accurate picture of college-student responding in the RFT (Series 3). It is not clear, however, as to whether or not the Neville et al (1969) frequency distribution is representative of psychiatric patients for reasons cited above. It would seem that before meaningful comparisons can be made, attention must be given to making sure that procedures do not vary from sample to sample.

\section{REFERENCES}

ADEVAI, G., SILVERMAN, A. J., \& McGOUGH, W. E. Perceptual correlates of the rod-and-frame test. Perceptual \& Motor Skills, $1968,26,1055+1064$.

LESTER, G. The rod-and-frame test; Some comments on methodology. Perceptual \& Motor Skills, 1968, 26, 1307-1314.

NEVILLE, C. W., WORKMAN, S. N., \& JOHNSON, D. T. Expected scores in the rod-and-frame test: lick dependence is where you find it. Psychonomic Science, 1969, 15, 321-322.

PRESSEY, A. W. A reply to comments on "Figural aftereffects, illusions, and the dimension of field dependence." Psychonomic Science, 1968, 11, 364 .

VAUGHT, G. M. Expected scores in the rod-and-frame test: Fuel for the Immergluck-Pressey fire. Psychonomic Science, 1968, 13, 248.

WITKIN, H. A. Psychological differentiation and forms of pathology. Journal of Abnormal Psychology, 1965, 70, 317-336.

WITKIN, H. A., DYK, R. B., FATERSON, H.. GOODENOUGH, D. R.. \& KARP, S. A. Psychological differentiation. New York: Wiley, 1962. 